\title{
Physical and Acoustical Properties of Corn Husk Fiber Panels
}

\author{
Nasmi Herlina Sari, ${ }^{1}$ I. N. G. Wardana, ${ }^{2}$ Yudy Surya Irawan, ${ }^{2}$ and Eko Siswanto \\ ${ }^{1}$ Department of Mechanical Engineering, Faculty of Engineering, Mataram University, Nusa Tenggara Barat, Indonesia \\ ${ }^{2}$ Department of Mechanical Engineering, Faculty of Engineering, Brawijaya University, East Java, Indonesia \\ Correspondence should be addressed to Nasmi Herlina Sari; n.herlinasari@unram.ac.id
}

Received 25 August 2016; Revised 14 November 2016; Accepted 21 November 2016

Academic Editor: Benjamin Soenarko

Copyright (C) 2016 Nasmi Herlina Sari et al. This is an open access article distributed under the Creative Commons Attribution License, which permits unrestricted use, distribution, and reproduction in any medium, provided the original work is properly cited.

\begin{abstract}
This research focuses on the development of a sustainable acoustic material comprising natural fibers of corn husk that were alkali modified by $1 \%, 2 \%, 5 \%$, and $8 \% \mathrm{NaOH}$. The morphology and the acoustical, physical, and mechanical properties of the resulting fibers were experimentally investigated. Five different types of sample were produced in panel form, the acoustical properties of which were studied using a two-microphone impedance tube test. The porosity, tortuosity, and airflow resistivity of each panel were investigated, tensile tests were conducted, and the morphological aspects were evaluated via scanning electron microscopy. The sound absorption and tensile properties of the treated panels were better than those of raw fiber panels; the treated panels were of high airflow resistivity and had low porosity. Scanning electron micrographs of the surfaces of the corn husk fibers revealed that the different sound absorption properties of these panels were due to roughness and the lumen structures.
\end{abstract}

\section{Introduction}

Currently, sound-absorbing materials mostly comprise synthetic and waste products, such as foams, recycled rubber, glass wool, and polyester fibers, which can be hazardous to human health, disruptive at workplaces, and harmful to the environment [1]. As such, it would be preferable if natural materials could be used instead. Natural fibers, with their porous cell structure and relatively low density, are becoming increasingly popular because they are renewable, nonabrasive, cheaper, and available in abundance and pose lower health risks during handling and processing $[2,3]$. Some applications (e.g., construction and furniture) have begun to use sound-absorbing panels comprising cellulose fibers from leaves, rice, hemp, coconut, or ramie [4-7]. However, such natural fibers tend to absorb a considerable amount of moisture. In addition, they are adversely affected by heat and microbes and are prone to decomposition [8]. Fortunately, several studies have reported that chemical treatment of the surfaces of natural fibers can reduce these disadvantages [911]. In particular, the effects of alkali treatment of natural fibers used in polymer composites have been discussed in relation to the physical and mechanical properties of such materials [12-14]. However, to date, few studies have investigated the effects of alkali treatment on the acoustic properties of the surface of natural fibers [3].

The acoustic properties of absorbent fibrous materials have been extensively studied. Delany and Bazley [15] investigated a range of such materials in relation to their characteristic impedances and propagation coefficients. Attenborough [16] used flow resistivity to study predictive models of the acoustic characteristics of rigid fibrous absorbent soils and sands. Biot $[17,18]$ formulated theories about the propagation of high- and low-frequency stress waves in porous elastic media containing a compressible viscous fluid. Bies and Hansen [19] characterized the acoustic performance of porous materials for common applications that are based on the measurement of airflow resistance. These previous studies showed that a better understanding of the microstructure and physical parameters of a material could help in developing high-performance acoustic materials.

This study investigates the acoustic and nonacoustic properties of the panels of corn husk fiber (CHF), which is a renewable bioresource and is thus biodegradable. Panels of CHF are compared with and without alkali treatment of the fibers. The concentration of alkali $(\mathrm{NaOH})$ is varied to analyze the changes in the mechanical properties and surface morphology of the fibers. 


\section{Materials and Methods}

2.1. Material. The main material used in this study was waste corn husk that had an average length and width of 240$245 \mathrm{~mm}$ and $110-135 \mathrm{~mm}$, respectively. The selection process was aimed at maintaining the uniformity of the selected CHFs.

2.2. Fiber Bundle Extraction. The corn husks were soaked in water for 16 days to undergo a process of microbacterial degradation. They were then washed thoroughly in fresh water and combed with a plastic brush in order to remove residue particles from the fibers surfaces and align the fibers equally. The retained inner layer was a bundle of fibers that could be separated for further use. Raw CHFs were retrieved, cleaned, and dried naturally in the air.

2.3. Alkaline Treatment of CHF. The CHFs were soaked in $1 \%, 2 \%, 5 \%$, or $8 \% \mathrm{NaOH}$ for $2 \mathrm{~h}$ in a standard atmosphere of $29^{\circ} \mathrm{C}$ and $64 \%$ relative humidity and subsequently rinsed five times with mineral water in order to remove $\mathrm{NaOH}$ from the fiber surfaces. They were dried in natural sunlight to remove any residual moisture and were then stored in plastic wrap. Subsequently, they were stored in a dry box with $40 \%$ humidity.

2.4. Fabrication of CHF Panels. Samples of raw and treated $\mathrm{CHF}$ were prepared and weighed using a digital analytical balance to gain fiber mass of $4.5 \times 10^{-3} \mathrm{~kg}$. Subsequent, the samples formed in a round mold with a diameter of $29 \mathrm{~mm}$ and thickness of $20 \mathrm{~mm}$. A compaction of $37 \mathrm{kPa}$ was used to form panel samples that were $29 \mathrm{~mm} \times 20 \mathrm{~mm}$ (diameter $x$ thickness). Five different samples were used for acoustical and porosity tests. The bulk density of each sample was measured by the ratio of the total mass $m$ of the sample $(\mathrm{Kg})$ and its volume $v\left(\mathrm{~m}^{3}\right)$ as $\rho_{\text {bulk }}=m / V$ [5]. Because the dimension of a fiber lumen is in microns, it is not detected in the measurement volume. The greater density of the sample, that is, more fibers with the same thickness, was detected to have pores size decreased. However, this could form a more complicated internal path (tortuosity) which can cause greater energy loss. A photograph of the corn husk panel samples is shown in Figure 1.

\subsection{Physical Properties}

2.5.1. Porosity. The connected porosity of the CHF panels was nonacoustically measured using water saturation, as illustrated by Vašina et al. [20] All the samples were dried at $105^{\circ} \mathrm{C}$ for one day. Subsequently, they were weighed before being left in a vacuum vessel to saturate under water (density of water $\rho_{w}=1000 \mathrm{~kg} / \mathrm{m}^{3}$ ). After $24 \mathrm{~h}$, they were carefully removed and weighed again. The porosity was computed using $\varepsilon=V_{w} / V_{s}$, where $V_{w}$ is the volume of the sample occupied by water and $V_{s}$ is the total volume of the sample. The volume of water can be calculated using the following: $V_{w}=\left(m_{\text {wet }}-m_{\text {dry }}\right) / \rho_{w}$, where $m_{\text {wet }}$ and $m_{\text {dry }}$ are the wet and dry masses $(\mathrm{kg})$ of the sample, respectively.
2.5.2. Airflow Resistivity. The airflow resistivity was based on the ASTM D-1564-1971 test. The flow resistivity was calculated using $[21,22]$

$$
\sigma=\frac{\left(6.8 \cdot \eta \cdot(1-\varepsilon)^{1,296}\right)}{\left(d^{2} \cdot \varepsilon^{3}\right)}
$$

where $\eta$ represents the viscosity of air $\left(1.84 \times 10^{-5} \mathrm{~Pa} \cdot \mathrm{s}\right), \varepsilon$ represents the porosity, and $d$ represents the radii of the fibers.

2.5.3. Tortuosity. The following empirical formula was used to calculate tortuosity $(\varphi)$ in terms of porosity $(\varepsilon)$ as follows [3]:

$$
\varphi=1+\frac{(1-\varepsilon)}{2 \varepsilon}
$$

2.6. Mechanical Properties. Single fibers were separated manually from the fiber bundles of raw and treated CHFs. The tensile strength and Young's modulus were determined using a Tensilon RTG 1310 universal testing machine with a load cell of $10 \mathrm{kN}$. All the fiber samples were tested after conditioning the samples for $24 \mathrm{~h}$ in a standard testing atmosphere of $28^{\circ} \mathrm{C}$ and $70 \%$ relative humidity. The sample length was $25 \mathrm{~mm}$, and a crosshead speed of $2 \mathrm{~mm} / \mathrm{min}$ was used for tensile testing, according to ASTM D-3379-75 [23]. In total, 15 samples were tested for each alkali treatment condition and the average and standard deviation values were reported. Prior to each test, the mean diameter of the fibers was measured to an accuracy of $0.001 \mathrm{~mm}$ using a Mitutoyo digital micrometer.

2.7. Sound Absorption Measurement. The acoustic properties of the material formed from the fibers were measured using a two-microphone transfer-function method, according to ISO 10534-2/ASTM E-1050-98 standards. The testing apparatus was part of complete acoustic material testing system, Brüel \& Kjær, as it is shown in Figure 2. A small tube setup was employed to measure different acoustical parameters in the frequency range of $100 \mathrm{~Hz}-6.4 \mathrm{kHz}$. At one end of the tube, a loudspeaker was situated to act as a sound source and the test material was placed at the other end to measure sound absorption properties. For precise fitting of samples into the measurement tube, an aluminum rod has a length of $40 \mathrm{~mm}$ and diameter of $29 \mathrm{~mm}$ and it was utilized to push the material into a preadjusted depth. Two acoustic microphones (type 4187, Brüel \& Kjær) were located in front of the sample to record the incident sound from the loudspeaker and the reflected sound from the material. The recorded signals in the analyzer in terms of the transfer function between the microphones were processed using Brüel \& Kjær material testing software to obtain the absorption coefficient of the sample under test. Each set of the experiments was repeated three times in order to have average measurements.

2.8. Scanning Electron Microscope. The surface morphologies of the raw and treated CHFs were observed using FEI Inspect S50 scanning electron microscope with a field emission gun. An accelerating voltage of $10 \mathrm{kV}$ was used to obtain SEM 


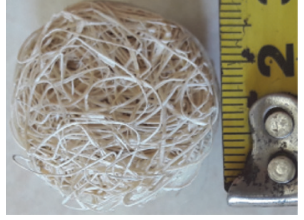

(a)

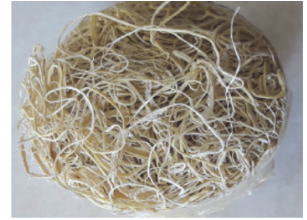

(b)

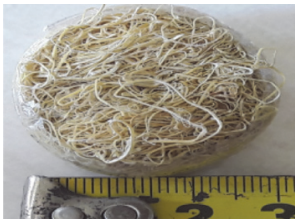

(c)

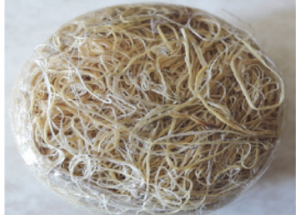

(d)

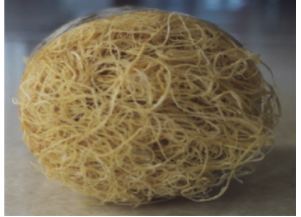

(e)

Figure 1: Photographs of the test panel sample. (a) Raw; (b) $1 \% \mathrm{NaOH}$; (c) $2 \% \mathrm{NaOH}$; (d) $5 \% \mathrm{NaOH}$; and (e) $8 \% \mathrm{NaOH}$.

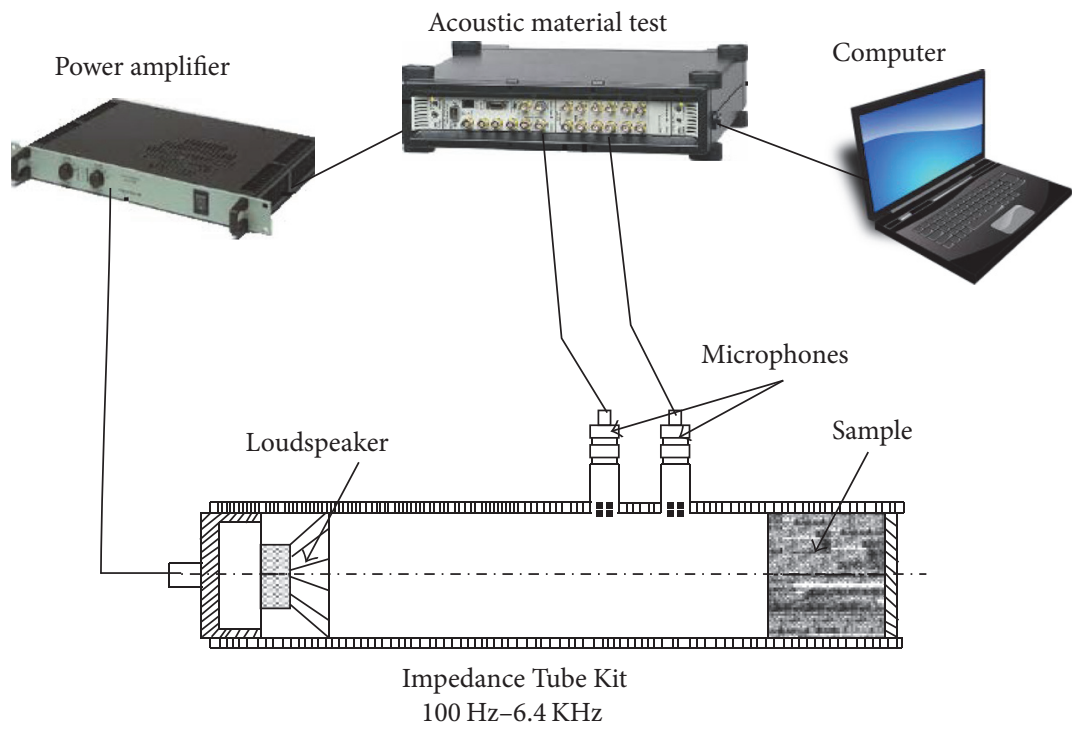

FIgURE 2: Impedance tube kit (type 4206, Brüel \& Kjær).

images of the surfaces of the raw and alkali-treated CHFs. Before testing, the samples were sliced and mounted on SEM stubs with double-sided adhesive tape. To make the samples conductive, they were gold sputtered for $5 \mathrm{~min}$ to a thickness of approximately $10 \mathrm{~nm}$ under a pressure of 0.1 torr and a current of $18 \mathrm{~mA}$. Micrographs were recorded at different magnifications to ensure clear images.

\section{Results and Discussion}

3.1. Physical Properties of CHF Panels. Large differences were observed in the physical properties of the CHF samples because of their different microstructures as a result of the chemical treatment of the raw fibers. This diversity is very interesting because it can provide considerably different porous microstructures and thus different acoustic properties. The values of porosity, tortuosity, and airflow resistivity are listed in Table 1.

The alkali treatment is increasing the airflow resistivity and decreasing the porosity of the panel. The porosity values show that the raw fibers are more porous than treated CHFs. The airflow resistivity and tortuosity of the treated samples are presumably higher than those of the raw sample. The CHF sample treated with $8 \% \mathrm{NaOH}$ has a higher resistivity and lower porosity than the CHF samples treated with $1 \%, 2 \%$, and $5 \% \mathrm{NaOH}$.
All the samples present an open pore structure wherein the pores are interconnected. This is one of the most important factors for noise absorption because such a structure increases airflow resistivity and thus the dissipation of the wave energy in the pores. In these samples, the multiscale fiber structure with lumina inside the fiber bundle has pores whose size can differ by many orders of magnitude (Figures $8(\mathrm{a})-8(\mathrm{j}))$.

3.2. Tensile Strength Properties. The tensile properties and the modulus of elasticity are compared for the raw and treated CHFs, as shown in Figures 3 and 4. The alkali treatment conducted by varying the concentration of $\mathrm{NaOH}$ from $1 \%$ to $8 \%$ increased the tensile strength and the modulus of elasticity. The tensile strength of a raw fiber was $160.49 \pm$ 17.12 MPa. Under treatment, this increased to between $230.90 \pm 41.85 \mathrm{MPa}$ and $368.25 \pm 78.97 \mathrm{MPa}$. The modulus of elasticity of a raw fiber was $4.57 \pm 0.54 \mathrm{GPa}$. Under treatment, this increased to between $7.09 \pm 0.52 \mathrm{GPa}$ and $15.87 \pm 1.87 \mathrm{GPa}$. These enhancements are related to a decrease in the fiber diameter, as shown in Figure 5. For CHF samples treated with $1 \% \mathrm{NaOH}$, the modulus of elasticity is higher than that for those treated with $2 \%$ and $5 \% \mathrm{NaOH}$, contributing to the sound absorption of the samples. The fibers treated with $8 \%$ $\mathrm{NaOH}$ had the best tensile performance, which is attributed to having the lowest diameter of $0.124 \pm 0.017 \mathrm{~mm}$. 
TABLE 1: Physical properties of samples.

\begin{tabular}{lccccc}
\hline Material $(\mathrm{CHFs})$ & $\begin{array}{c}\text { Thickness }(t) \\
(\mathrm{mm})\end{array}$ & $\begin{array}{c}\text { Density } \\
\left(\mathrm{Kg} \cdot \mathrm{m}^{-3}\right)\end{array}$ & $\begin{array}{c}\text { Porosity } \\
(\varepsilon)\end{array}$ & $\begin{array}{c}\text { Airflow resistivity }(\sigma) \\
\left(\mathrm{Pa} \cdot \mathrm{s} \cdot \mathrm{m}^{-2}\right)\end{array}$ & $\begin{array}{c}\text { Tortuosity } \\
(\varphi)\end{array}$ \\
\hline Raw & 20 & 344 & $0.88 \pm 0.02$ & $1375 \pm 332$ & $1.06 \pm 0.01$ \\
Treated $(1 \% \mathrm{NaOH})$ & 20 & 438 & $0.87 \pm 0.01$ & $1885 \pm 93$ & $1.07 \pm 0.01$ \\
Treated $(2 \% \mathrm{NaOH})$ & 20 & 566 & $0.86 \pm 0.00$ & $2540 \pm 44$ & $1.08 \pm 0.01$ \\
Treated $(5 \% \mathrm{NaOH})$ & 20 & 584 & $0.82 \pm 0.01$ & $5572 \pm 157$ & $1.11 \pm 0.01$ \\
Treated $(8 \% \mathrm{NaOH})$ & 20 & 615 & $0.77 \pm 0.01$ & $11.118 \pm 462$ & $1.15 \pm 0.01$ \\
\hline
\end{tabular}

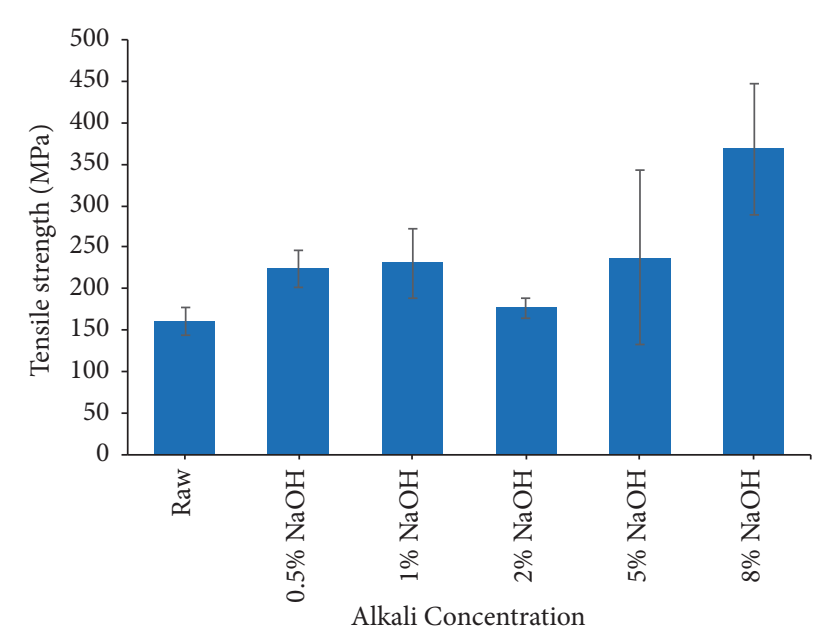

FIGURE 3: Ultimate tensile strengths of raw and treated of corn husk fiber (CHF) bundles.

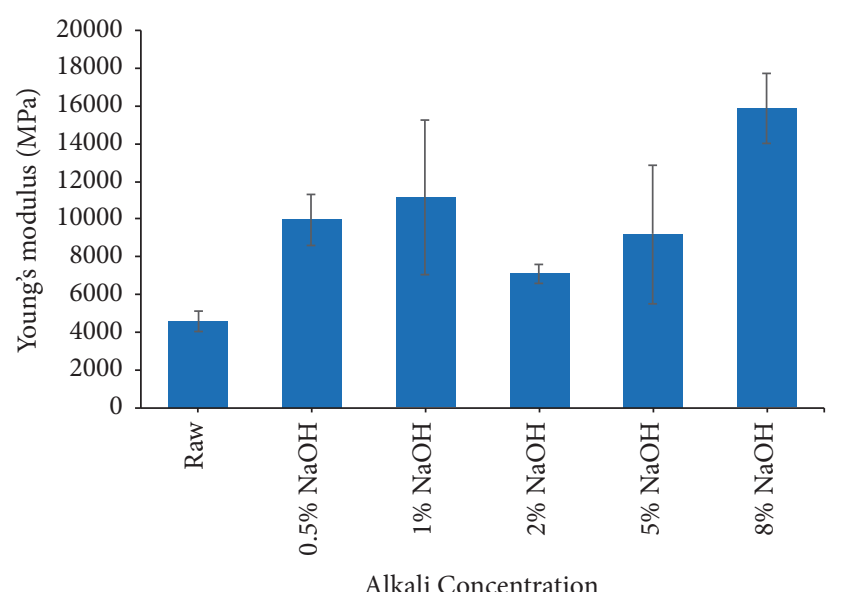

Figure 4: Moduli of elasticity of raw and treated CHF bundles.

Obi Reddy et al. [24] and Suryanto et al. [25] reported similar investigations but with different fibers. They stated that the increase in tensile strength is indeed due to the reduction in fiber diameter, which in turn is due to the loss of the hemicellulose and lignin parts of the cellulose and the associated moisture content of fiber brought about by the alkaline treatment. Hossain et al. [26] stated that the chemical treatment increases the aspect ratio and surface roughness of the fibers, thereby increasing their tensile strength. This may

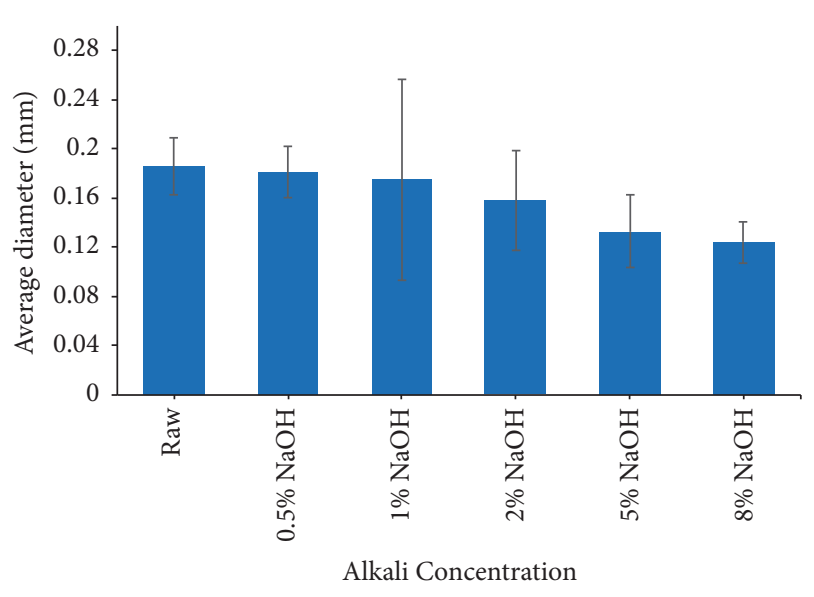

FIGURE 5: Variation in the diameters of CHF bundles.

also explain why the CHFs treated with $8 \% \mathrm{NaOH}$ had the lowest diameter and highest tensile strength.

3.3. Sound Absorption Analysis of CHF Panel. Cellular lumina form numerous interconnected pores. When a sound wave strikes a fibrous sound absorber, it causes the fibers of the absorbing material to vibrate, generating a tiny amount of heat because of internal friction between the fibers. The sound waves propagate vibration energy through the air spaces in the individual lumina inside the fiber. A portion of this sound energy is converted into heat in the lumina, which is then absorbed by the surrounding walls. Subjecting a sample to a pressure of $37 \mathrm{kPa}$ does not change its physical properties because of the mechanical strength of the CHFs in a range $160.49-368.25 \mathrm{MPa}$. Therefore, there is no change in the surface impedance of a sample as a result of compaction.

Figure 6 shows the variation of absorption coefficient with frequency for $\mathrm{NaOH}$-treated fiber panels. Increasing the $\mathrm{NaOH}$ concentration from $1 \%$ to $8 \%$ improves the sound absorption of the CHF panels. For the raw fibers, the maximum sound absorption coefficient is 0.93 (over $1.6-3 \mathrm{kHz}$ ), whereas, for the alkali-treated samples, it is 0.98-0.99 (over $1.6-3.25 \mathrm{kHz}$ ). This suggests that the alkali treatment changes the fiber elasticity and reduces the fiber diameter, thereby increasing the airflow resistivity and decreasing the porosity of the panel (Table 1). Moreover, for a constant fiber volume fraction, fibers having smaller diameter are more numerous than those having a larger diameter. Therefore, because the number of fibers per unit area increases as the fiber diameter 


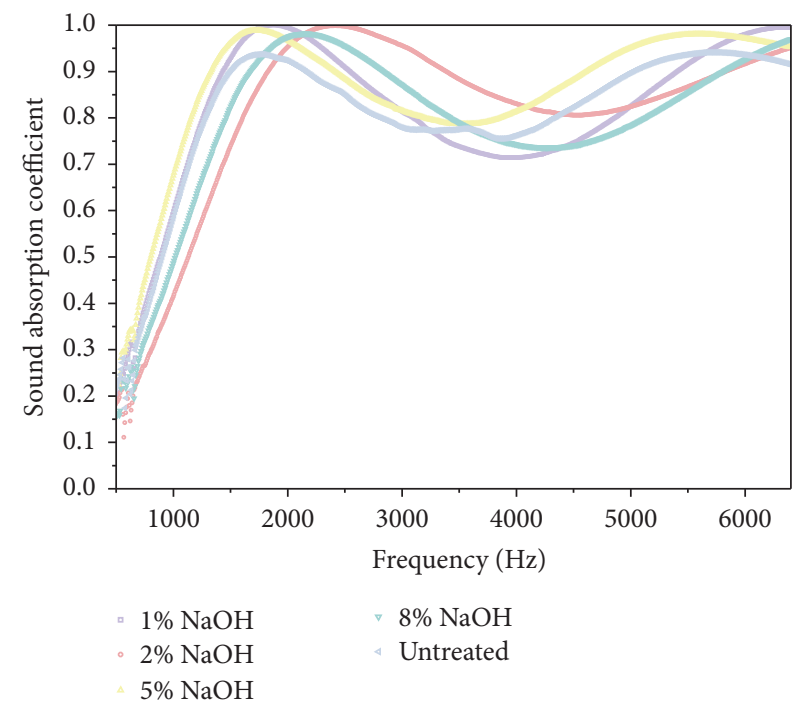

Figure 6: Sound absorption coefficients of CHF panels.

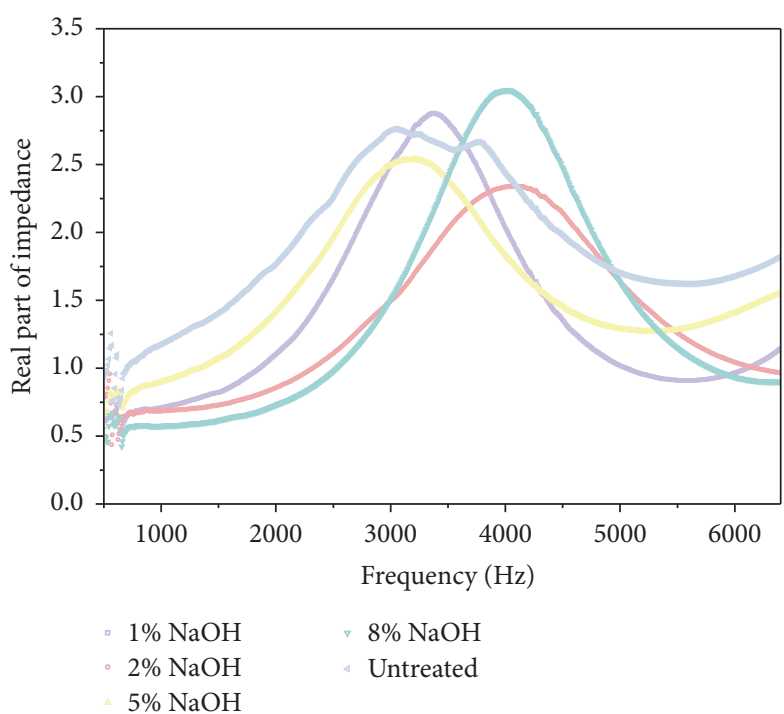

(a)

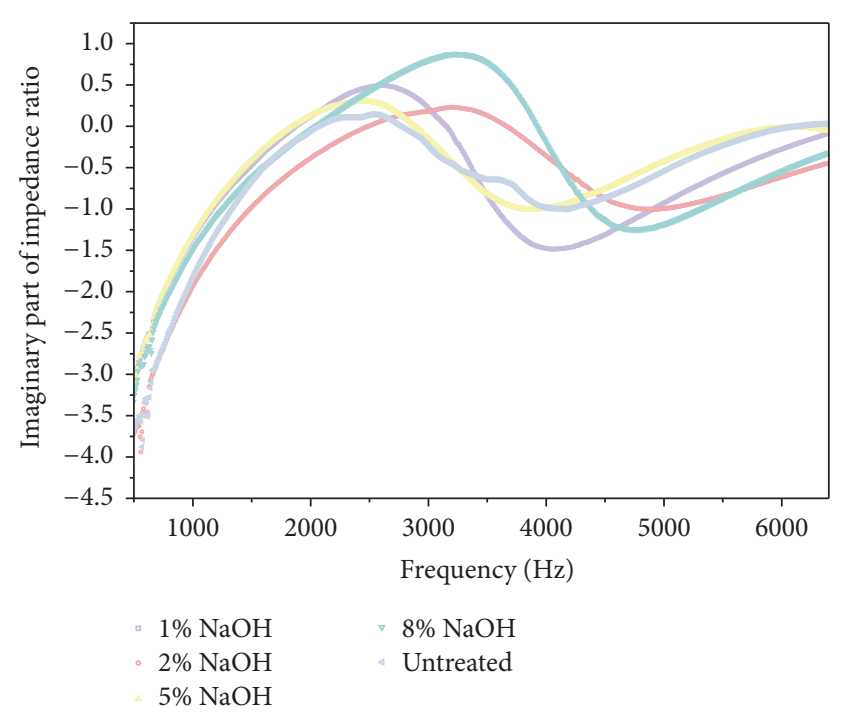

(b)

FIGURE 7: (a) Real part and (b) imaginary part of the impedance ratio of samples.

decreases, the additional thermal energy is dissipated more rapidly due to the increased frictional surface area. The sound absorption coefficient is therefore correspondingly higher than those of the raw sample. Presumably, the larger the air cavities and lumina inside the fiber, the higher the wavelength of the sound that is absorbed, which therefore lowers the sound absorption frequency (over $1.6-3.25 \mathrm{kHz}$ ). In contrast, because of the tightly arranged structure of the raw fibers, the incident sound waves are reflected more. Chen et al. [27] stated that pectin, lignin, hemicellulose, and other lowmolecular-weight materials can form a dense layer on the surface of fibers, thereby enhancing reflection. This would also explain why the sound absorption coefficient of raw fibers is lower than those of treated fibers, even though the structural patterns of the two types of fiber are similar.
For the samples treated with $5 \%$ and $8 \% \mathrm{NaOH}$, although the diameters of the treated fibers are smaller than those of the raw fibers, the treated fibers have a higher Young's modulus. In such circumstances, the increase in airflow resistance and tortuosity due to treatment is accompanied by an increase in stiffness. Therefore, movements of the sound are difficult to pass through the samples. This leads to a decrease in the absorption performance of the samples. However, for the high-frequency range above $5 \mathrm{kHz}$, the treated samples show better sound absorption performance. This is related to the random distribution of fibers in the panel, which enhances the absorption of sound waves. For a thickness of $20 \mathrm{~mm}$ and a fiber weight of $4.5 \times 10^{-3} \mathrm{~kg}$, the absorption coefficient is 0.8 in the frequency range of $1.3-6 \mathrm{kHz}$, which is better than that for other fibers such as paddy waste fibers. Putra et al. 


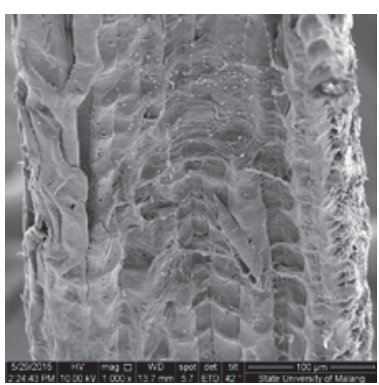

(a)

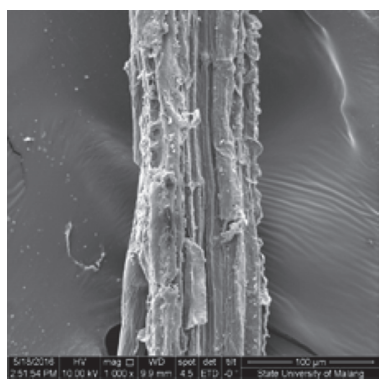

(c)

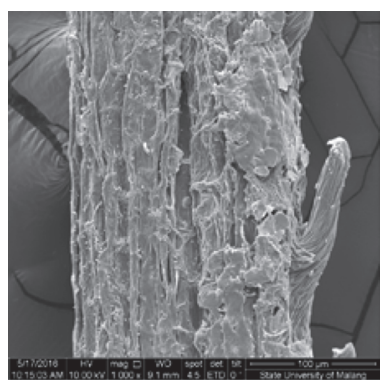

(e)

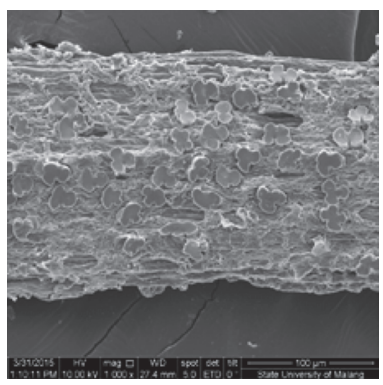

(g)

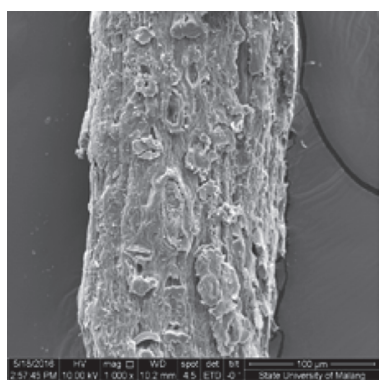

(i)

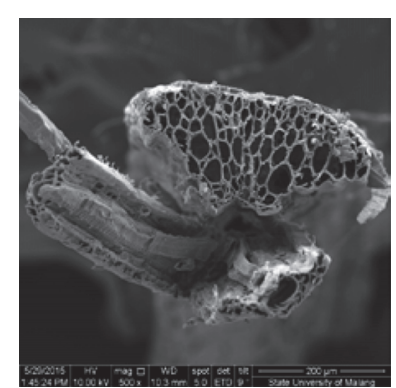

(b)

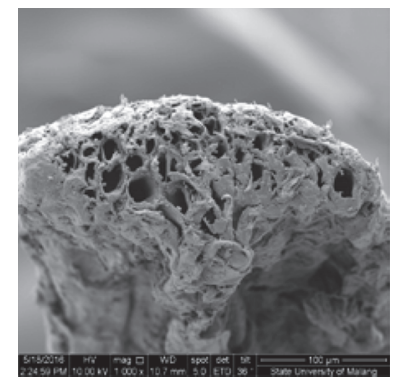

(d)

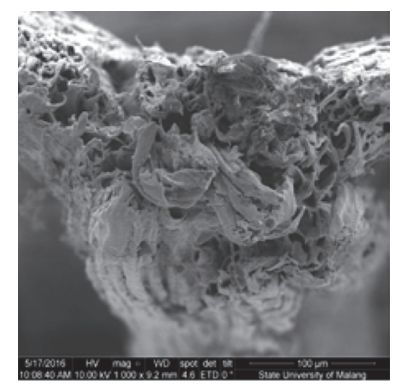

(f)

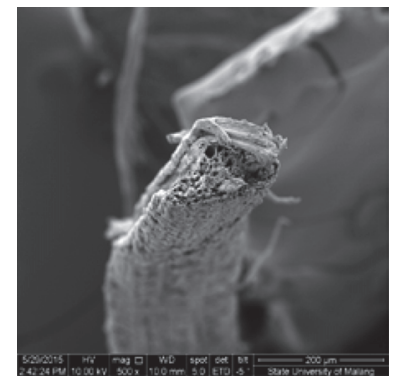

(h)

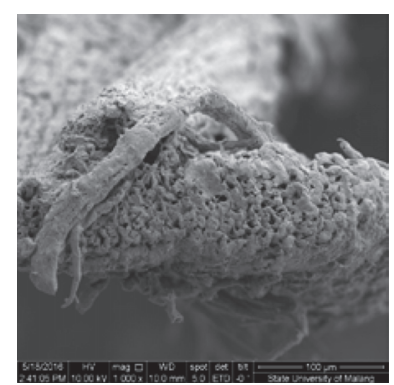

(j)

Figure 8: Scanning electron microscope (SEM) images of CHF: (a, b) raw and treated fibers, (c, d) $1 \% \mathrm{NaOH},(\mathrm{e}, \mathrm{f}) 2 \% \mathrm{NaOH},(\mathrm{g}, \mathrm{h}) 5 \%$ $\mathrm{NaOH}$, and $(\mathrm{i}, \mathrm{j}) 8 \% \mathrm{NaOH}$. 
[5] showed that paddy waste fibers with a thickness of $20 \mathrm{~mm}$ and a fiber weight of $5 \times 10^{-3} \mathrm{~kg}$ had a sound absorption coefficient of 0.7 in the frequency range of $2-5 \mathrm{kHz}$. It proves that the CHF panel can be a good alternative and a sustainable acoustic material. Furthermore, sound absorption at lower frequencies (over $1.6-3.25 \mathrm{kHz}$ ) is desirable for automotive applications because this frequency range corresponds to noise from the wind, tires, road, conversation, and engine running, thereby making $\mathrm{CHF}$ a promising candidate for automotive interior sound absorption.

Figures $7(\mathrm{a})$ and $7(\mathrm{~b})$ show the real and imaginary parts, respectively, of the acoustic impedance obtained from different samples. The real part is the resistance associated with energy losses, and the imaginary part is the reactance associated with phase changes. In this case, we see a better performance for the panels treated with $2 \%$ and $5 \% \mathrm{NaOH}$. Increasing the alkali treatment concentration reduces the impedance values, which in turn increase the fraction of wave energy that can be transmitted into the material.

3.4. Morphology Analysis. The scanning electron micrographs of the raw and treated CHF surfaces are shown in Figure 8. As shown in Figure 8(a), the surfaces of raw CHFs have impurities and shallow grooves. The only crevices that are apparent are minute ones. However, from observations of the fiber cross sections, we noticed a fiber structure comprising dense hollows (called lumina) inside the fiber bundles (Figure $8(\mathrm{~b})$ ).

An average lumen diameter of $1.2 \mu \mathrm{m}$ was calculated using the ImageJ software. This hollow structure (lumen) has a certain effect on the empty space for sound absorption. The sound waves propagate vibration energy through the air cavities and lumina inside the fiber. The unique lumen structure helps natural fibers to absorb sound.

The scanning electron micrographs show significant changes in surface morphology after applying $\mathrm{NaOH}$ treatment (Figures $8(\mathrm{c})-8(\mathrm{j}))$. As the percentage of $\mathrm{NaOH}$ on the CHF surfaces is increased, more hemicellulose and lignin are lost, which increases the sound absorption. The alkali treatment removes impurities, causing the fibers to separate. This leads to rougher surfaces and hence causes fibrillation, as shown in Figures 8(c), 8(e), 8(g), and 8(i), which enhances the mechanical and acoustical properties. From observations of the cross sections of the treated fibers, we observed that the average diameter of the lumina inside the fiber decreases (Figures $8(\mathrm{~d}), 8(\mathrm{f}), 8(\mathrm{~h})$, and $8(\mathrm{j})$ ). For example, fibers treated with $5 \% \mathrm{NaOH}$ have an average lumen diameter of $2.51 \mu \mathrm{m}$. Reduction in lumen diameter is certain to improve the acoustical properties of the panel.

There are numerous micropores in the porous structure of a single fiber bundle. When a sound wave impinges on the porous structure of the fibrous panel, the air motion and compression in the lumina caused by the sound vibration can cause friction on the lumen walls, thereby inhibiting movement of the air that is close to the lumen walls. Because of the frictional and viscous forces, a considerable fraction of the sound energy is converted into heat, which attenuates the acoustic energy. Heat loss due to heat exchange between the air in a lumen and the lumen walls can also cause sound energy attenuation. The random distribution of the fibers in the fibrous absorber panel allows more sound waves to impinge on the lumina of the fiber bundle, thereby strengthening the sound absorption. These special lumen structures and their distribution are the main reasons for the acoustical absorptivity.

\section{Conclusions}

The use of corn husk fiber for sound absorption was reported herein. The material is natural and renewable and is a waste product of corn husk processing that poses no harm to human health. All the samples studied could absorb sound. The alkali treatment of the fibers with $\mathrm{NaOH}$ had an effect of decreasing the fiber diameter, thereby improving the mechanical and acoustic properties of the CHF panels. The sound absorption approached $100 \%$ in the low-frequency range of 1.6-3.250 kHz for fiber samples that were treated with $2 \%$ and $5 \% \mathrm{NaOH}$ concentrates. Panels of treated fibers were better in absorbing sound than the panels of raw fibers. In addition, the alkali treatment helped to maintain the panel shape and protect it the panel shape of fiber damage.

We note that the CHF test samples used throughout this work were not combined as polymer materials. Future work could involve studying the effect of fiber volume fraction on the sound absorption properties of CHF composite materials.

\section{Competing Interests}

The authors declare that there is no conflict of interests regarding the publication of this paper.

\section{References}

[1] R. Zulkifli, Zulkarnain, and M. J. M. Nor, "Noise control using coconut coir fiber sound absorber with porous layer backing and perforated panel," American Journal of Applied Sciences, vol. 7, no. 2, pp. 260-264, 2010.

[2] A. P. Jorge and C. J. Malcolm, "Recent trends in porous soundabsorbing materials," Sound and Vibration, vol. 44, no. 7, pp. 1218, 2010.

[3] S. Fatima and A. R. Mohanty, "Acoustical and fire-retardant properties of jute composite materials," Applied Acoustics, vol. 72, no. 2-3, pp. 108-114, 2011.

[4] M. Küçük and Y. Korkmaz, "The effect of physical parameters on sound absorption properties of natural fiber mixed nonwoven composites," Textile Research Journal, vol. 82, no. 20, pp. 2043-2053, 2012.

[5] A. Putra, Y. Abdullah, H. Efendy, W. M. F. W. Mohamad, and N. L. Salleh, "Biomass from paddy waste fibers as sustainable acoustic material," Advances in Acoustics and Vibration, vol. 2013, Article ID 605932, 7 pages, 2013.

[6] U. Berardi and G. Iannace, "Acoustic characterization of natural fibers for sound absorption applications," Building and Environment, vol. 94, pp. 840-852, 2015.

[7] S. Ersoy and H. Küçük, "Investigation of industrial tea-leaffibre waste material for its sound absorption properties," Applied Acoustics, vol. 70, no. 1, pp. 215-220, 2009. 
[8] M. S. Salit, “Tropical natural fibres and their properties," in Tropical Natural Fibre Composites, Engineering Materials, pp. 15-38, Springer Singapore, Singapore, 2014.

[9] P. Saha, S. Manna, S. R. Chowdhury, R. Sen, D. Roy, and B. Adhikari, "Enhancement of tensile strength of lignocellulosic jute fibers by alkali-steam treatment," Bioresource Technology, vol. 101, no. 9, pp. 3182-3187, 2010.

[10] M. F. Rosa, B.-S. Chiou, E. S. Medeiros et al., "Effect of fiber treatments on tensile and thermal properties of starch/ethylene vinyl alcohol copolymers/coir biocomposites," Bioresource Technology, vol. 100, no. 21, pp. 5196-5202, 2009.

[11] D. Shanmugam and M. Thiruchitrambalam, "Static and dynamic mechanical properties of alkali treated unidirectional continuous Palmyra Palm Leaf Stalk Fiber/jute fiber reinforced hybrid polyester composites," Materials \& Design, vol. 50, pp. 533-542, 2013.

[12] H. Ku, H. Wang, N. Pattarachaiyakoop, and M. Trada, "A review on the tensile properties of natural fiber reinforced polymer composites," Composites Part B: Engineering, vol. 42, no. 4, pp. 856-873, 2011.

[13] P. Pantamanatsopa, W. Ariyawiriyanan, T. Meekeaw et al., "Effect of modified jute fiber on mechanical properties of green rubber composite," Energy Procedia, vol. 56, pp. 641-647, 2014.

[14] A. R. S. Neto, M. A. M. Araujo, R. M. P. Barboza et al., "Comparative study of 12 pineapple leaf fiber varieties for use as mechanical reinforcement in polymer composites," Industrial Crops and Products, vol. 64, pp. 68-78, 2015.

[15] M. E. Delany and E. N. Bazley, "Acoustical properties of fibrous absorbent materials," Applied Acoustics, vol. 3, no. 2, pp. 105-116, 1970.

[16] K. Attenborough, "Acoustical characteristics of rigid fibrous absorbents and granular materials," The Journal of the Acoustical Society of America, vol. 73, no. 3, pp. 785-799, 1983.

[17] M. A. Biot, "Theory of propagation of elastic waves in a fluidsaturated porous solid. II. Higher frequency range," The Journal of the Acoustical Society of America, vol. 28, no. 2, pp. 179-191, 1956.

[18] M. A. Biot, "Theory of propagation of elastic waves in a fluidsaturated porous solid. I. Low-frequency range," The Journal of the Acoustical Society of America, vol. 28, pp. 168-178, 1956.

[19] D. A. Bies and C. H. Hansen, "Flow resistance information for acoustical design," Applied Acoustics, vol. 13, no. 5, pp. 357-391, 1980.

[20] M. Vašina, D. C. Hughes, K. V. Horoshenkov, and L. Lapčík Jr., "The acoustical properties of consolidated expanded clay granulates," Applied Acoustics, vol. 67, no. 8, pp. 787-796, 2006.

[21] F. P. Mechel, Formulas of Acoustics, Springer, Berlin, Germany, 2nd edition, 2008.

[22] R. Maderuelo-Sanz, A. V. Nadal-Gisbert, J. E. Crespo-Amorós, and F. Parres-García, "A novel sound absorber with recycled fibers coming from end of life tires (ELTs)," Applied Acoustics, vol. 73, no. 4, pp. 402-408, 2012.

[23] A. Alawar, A. M. Hamed, and K. Al-Kaabi, "Characterization of treated date palm tree fiber as composite reinforcement," Composites Part B: Engineering, vol. 40, no. 7, pp. 601-606, 2009.

[24] K. Obi Reddy, C. Uma Maheswari, M. Shukla, J. I. Song, and A. Varada Rajulu, "Tensile and structural characterization of alkali treated Borassus fruit fine fibers," Composites Part B: Engineering, vol. 44, no. 1, pp. 433-438, 2013.

[25] H. Suryanto, E. Marsyahyo, Y. S. Irawan, and R. Soenoko, "Morphology, structure, and mechanical properties of natural cellulose fiber from mendong grass (Fimbristylis globulosa)," Journal of Natural Fibers, vol. 11, no. 4, pp. 333-351, 2014.

[26] M. K. Hossain, M. R. Karim, M. R. Chowdhury et al., "Comparative mechanical and thermal study of chemically treated and untreated single sugarcane fiber bundle," Industrial Crops and Products, vol. 58, pp. 78-90, 2014.

[27] D. Chen, J. Li, and J. Ren, "Study on sound absorption property of ramie fiber reinforced poly(L-lactic acid) composites: morphology and properties," Composites Part A: Applied Science and Manufacturing, vol. 41, no. 8, pp. 1012-1018, 2010. 


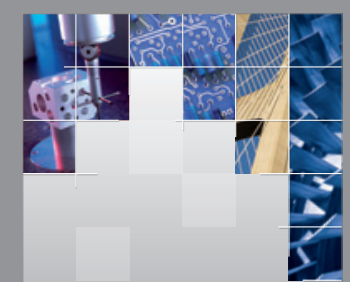

\section{Enfincering}
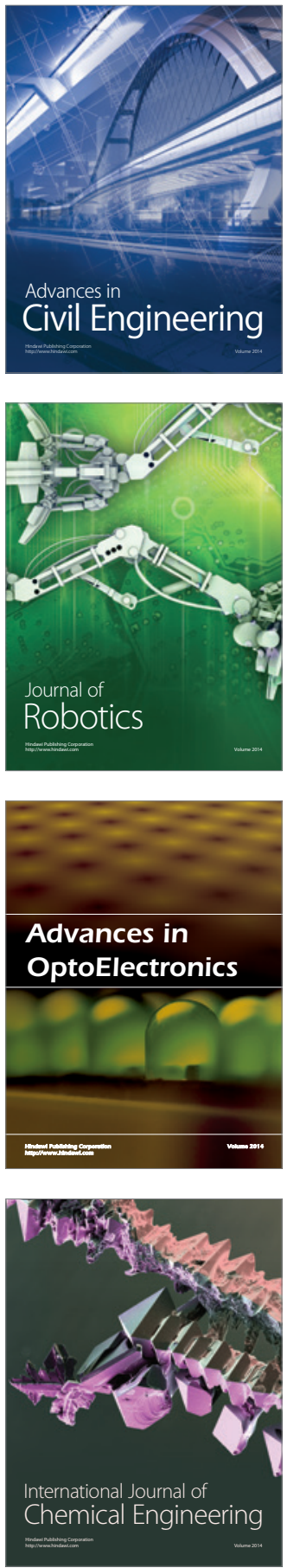

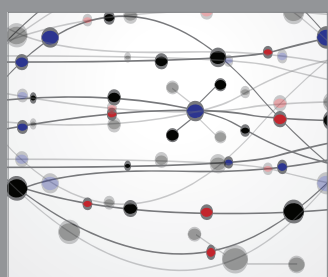

The Scientific World Journal

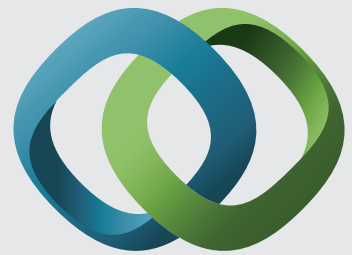

\section{Hindawi}

Submit your manuscripts at

http://www.hindawi.com
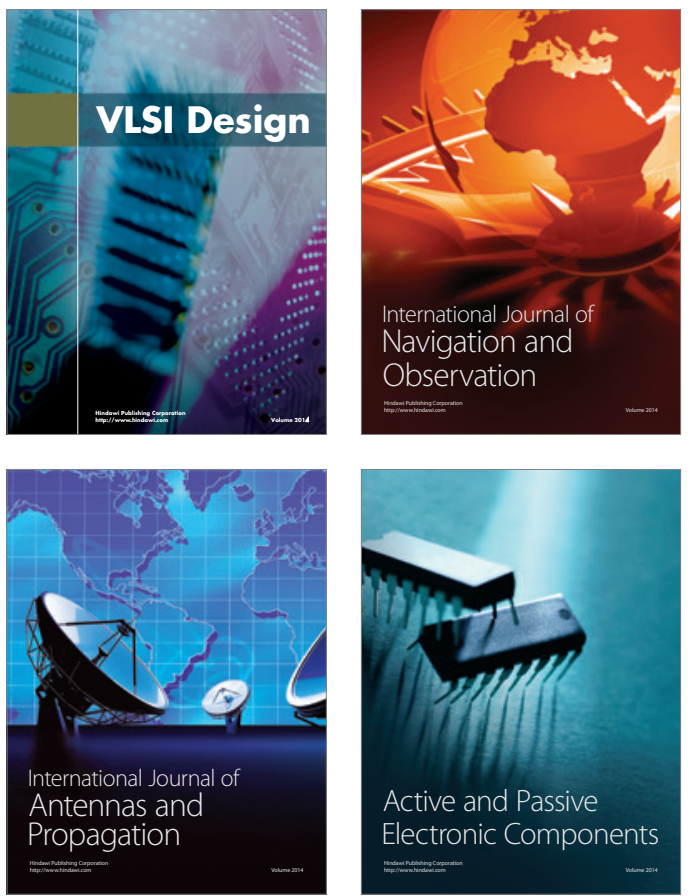
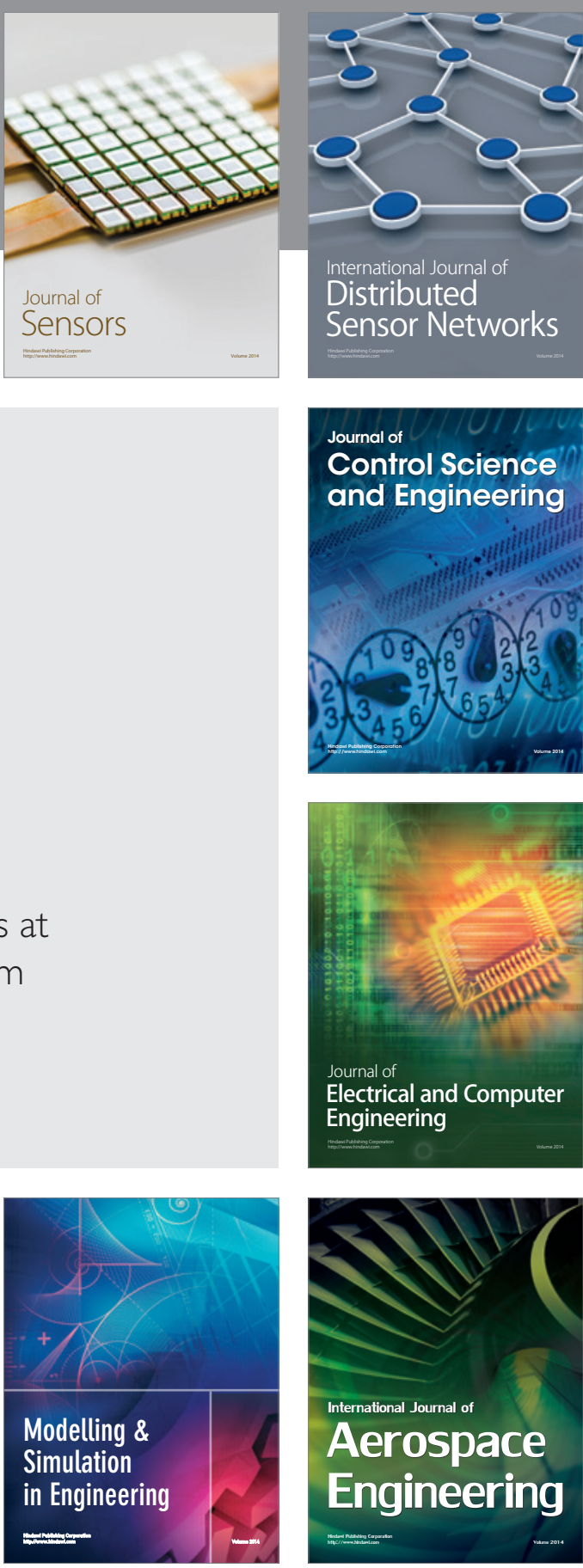

International Journal of

Distributed

Sensor Networks

Journal of

Control Science

and Engineering
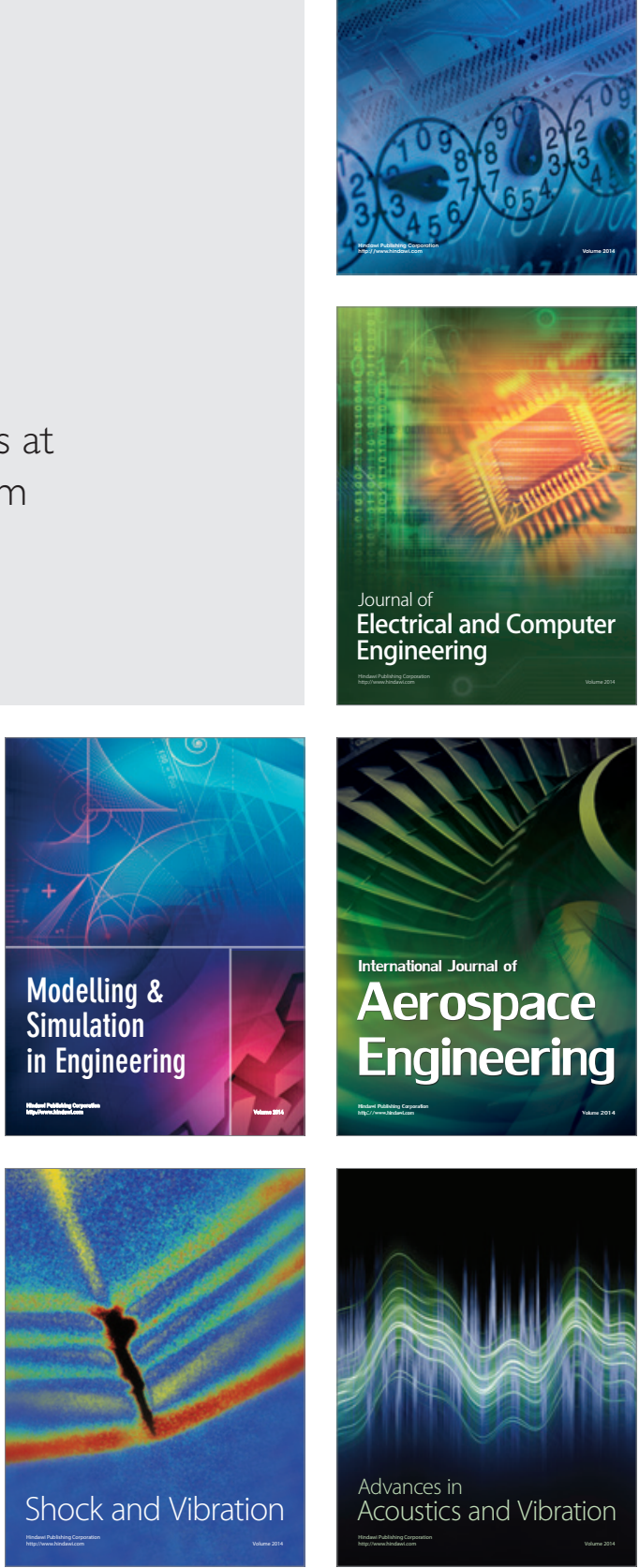